\title{
SEDIMENTOLOGY AND STRATIGRAPHY OF THE AMAZON CONTINENTAL SHELF
}

By Charles A. Nittrouer, Steven A. Kuehl, James M. Rine, Alberto G. Figueiredo, L. Ercilio C. Faria, Gilberto T.M. Dias, M. Augusta M. Silva, Mead A. Allison, Thomas D. Pacioni, Marylin P. Segall, Ellen C. Underkoffler, Heloisa V. Borges and Odete F. Silveira

$T$ HE GENERAL objective of this portion of AmasSeds (A Multidisciplinary Amazon Shelf SEDiment Study) is to understand how evidence of environmental processes influencing the Amazon shelf is preserved in the underlying sedimentary strata. Unfortunately, strata are imperfect recorders of environmental events. In oceanic settings near large sediment sources, net accumulation of sediment may occur; however, in a physically dynamic setting, the preserved strata may contain numerous breaks of non-deposition or erosion. A fundamental question concerns what environmental interpretations are possible from sedimentary sequences which are punctuated by missing strata. This question assumes additional importance when a setting, such as the Amazon shelf, records the history for much of a continent and an equatorial ocean.

In order to meet the general objective and to build on existing knowledge, several specific objectives are being undertaken by this project. The first is to identify the dominant processes (e.g., tidal currents, river discharge, bioturbation) controlling strata formation on different time and vertical-length scales. These scales range from hours to millenia and from microns to tens of meters. Secondly, the project is attempting to determine how the oceanic processes operate on sediment (rework, sort, bury) to emplace char-

C.A. Nittrouer, J.M. Rine, M.A. Allison, Marine Sciences Research Center, State University of New York, Stony Brook, NY, 11794 USA. S.A. Kuehl, T.D. Pacioni, M.P. Segall, E.C. Underkoffler, Department of Geological Sciences, University of South Carolina, Columbia, SC, 29208 USA. A.G. Figueiredo, G.T.M. Dias, M.A.M. Silva, H.V. Borges. Departamento de Geologia, Universidade Federal Fluminense, Niteroi, RJ, 24260 Brasil. L.E.C. Faria, O.F. Silveira, Departamento de Geologia, Universidade Federal do Pará, Belém, PA, 66050 Brasil. acteristics within preserved strata. Both of these objectives require close involvement with the other research groups in AmasSeds. A third objective is to understand how partial preservation of strata affects interpretation of environmental settings and processes. This will help to impart geological relevance to the AmasSeds program.

\section{Approach}

In marine settings where the seabed is accreting, the sedimentary record is constructed from building blocks of successively larger scale; numerous small blocks become integral components for a block of the next larger scale. As an example relevant to the present study, sediment accumulated during semidiurnal tidal cycles can form distinctively different sedimentary units for spring versus neap tidal periods. Spring and neap units can create seasonal units, which in turn produce annual sedimentary units. Ultimately these successive units will form a deposit representing the present high sea-level conditions for a location, although in the process some units may be lost to erosion and some distinctions between units may be destroyed by bioturbation.

A general understanding of strata formation requires the evaluation of formative processes on numerous vertical-length and time scales. This leads the present project to a series of sampling and analytical techniques which telescope to progressively larger and longer scales. Coring techniques range from the collection of box cores (0.5$\mathrm{m}$ length) to kasten cores (3-m length) to piston cores (12-m length). Stratigraphic character is investigated by microfabric studies (microns to millimeters), $x$-radiography (millimeters to meters), and high-resolution seismic studies (meters to tens of meters). Time-series sampling ranges from anchor stations (coring every $2 \mathrm{~h}$ for about $24 \mathrm{~h}$ ) to
A

fundamental

question concerns

what environmental

interpretations are

possible from

sedimentary

sequences which are

punctuated by missing

strata. 
... relatively minor

changes in the seabed

on diurnal time scales,

but much more distinct

changes on fortnightly

(spring-neap) scales. reoccupation of anchor stations at fortnightly intervals to reoccupation of many stations at seasonal (3-mo) intervals. Chronology is examined by ${ }^{234} \mathrm{Th}$ (weeks to months), ${ }^{210} \mathrm{~Pb}$ (years to decades), and ${ }^{14} \mathrm{C}$ (centuries to millenia). Because stations are reoccupied to examine temporal variability in sedimentary processes, good positioning (GPS) and much replicate sampling is used to distinguish temporal and small-scale spatial variability.

Approximately $80 \%$ of the field effort is being expended in research vessels on the continental shelf. This allows close cooperation with the other oceanographic disciplines involved in AmasSeds. About $20 \%$ of the research is being undertaken from inflatable boats along the shoreline of Amapá (the Brazilian state north of the river mouth). In the past, water-depth limitations of oceanographic research vessels have restricted seabed sampling to areas seaward of about the $10-\mathrm{m}$ isobath. Because of these limitations, the Amapá shoreline had not been examined prior to AmasSeds, although coastal accretion was thought to be a potential sink for a significant fraction of Amazon sediment.

\section{Observations}

Much new knowledge about the sedimentology and stratigraphy of the Amazon shelf is being revealed through the AmasSeds project. Some of this new information is described below, and can be put in perspective with previous work introduced by Nittrouer et al. (this issue) and more thoroughly summarized in Nittrouer and DeMaster (1986).

\section{The Subaqueous Topset Region}

Observations at anchor stations on the RiverMouth Transect (for locations of transects see Nittrouer et al., this issue) reveal relatively minor changes in the seabed on diurnal time scales, but much more distinct changes on fortnightly (spring-neap) scales. In March 1990, the surficial seabed was characterized by sandy layers (several centimeters thick) during spring tides, and by soft muddy layers (5-15 cm thick) during neap tides. The changes within the seabed from spring to neap tidal conditions corresponded to decreases in the near-bottom current velocity and generally in suspended-sediment concentration, as observed by the Physical-Oceanography and SedimentTransport groups of AmasSeds. These relationships help to explain interbedding of sand and mud which characterizes shelf strata near the mouth of the Amazon (Fig. 1).

${ }^{210} \mathrm{~Pb}$ profiles for the shelf region between about 10 to $30 \mathrm{~m}$ water depth reveal a thick $(60-150$ $\mathrm{cm}$ ) layer of nearly uniform excess activity at the surface (Fig. 2). The layer is probably the result of physical processes (e.g., erosion, deposition), because, on this portion of the Amazon shelf, generally few benthic organisms are present and

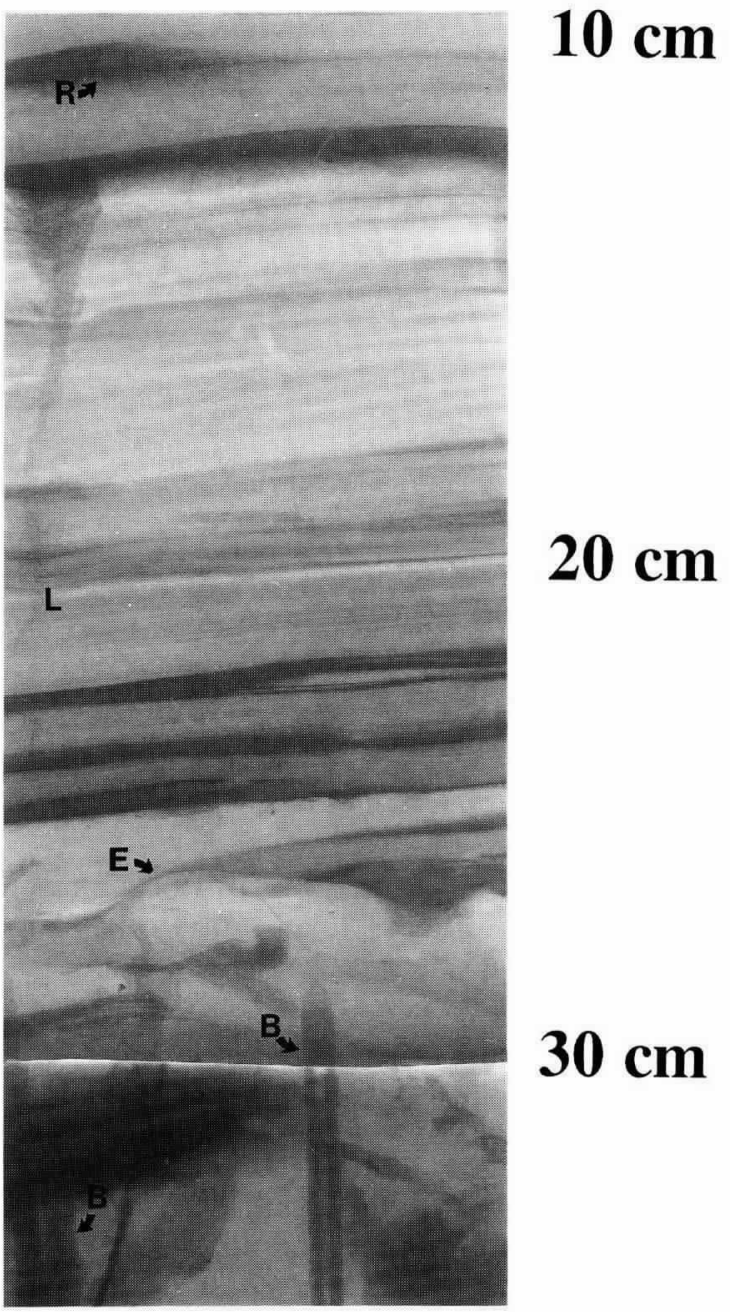

Fig. 1: An x-radiograph (positive) of sand/coarse silt (dark) and mud (light gray) laminae, which illustrates the typical sedimentary features preserved within the topset strata on the continental shelf near the mouth of the Amazon River. Features present are lenticular ripples $(R)$, thin laminae (L), and an erosional contact (E) capping sand-lined burrows (B) of mud-shrimp (Thalassinids). Fluctuating environmental conditions on the time scales of spring-neap tidal variations are, at least in part, the cause of the interlayered sand and mud. Erosional contacts, such as the one shown here, indicate major periods of strata removal that appear to reoccur on time scales greater than seasonal but less than ten's of years.

few biological structures are observed in x-radiographs. Thicknesses of the layer in replicate cores are highly reproducible $( \pm 5 \mathrm{~cm})$, indicating that small-scale lateral variability of the layer (over 100 's of meters) is generally not significant. The thickness in most locations decreases only about $20 \mathrm{~cm}$ between periods of peak river discharge and lower flow. Therefore, the bulk of the thickness for this surficial layer is not related to seasonal deposition and removal. However, most of the 


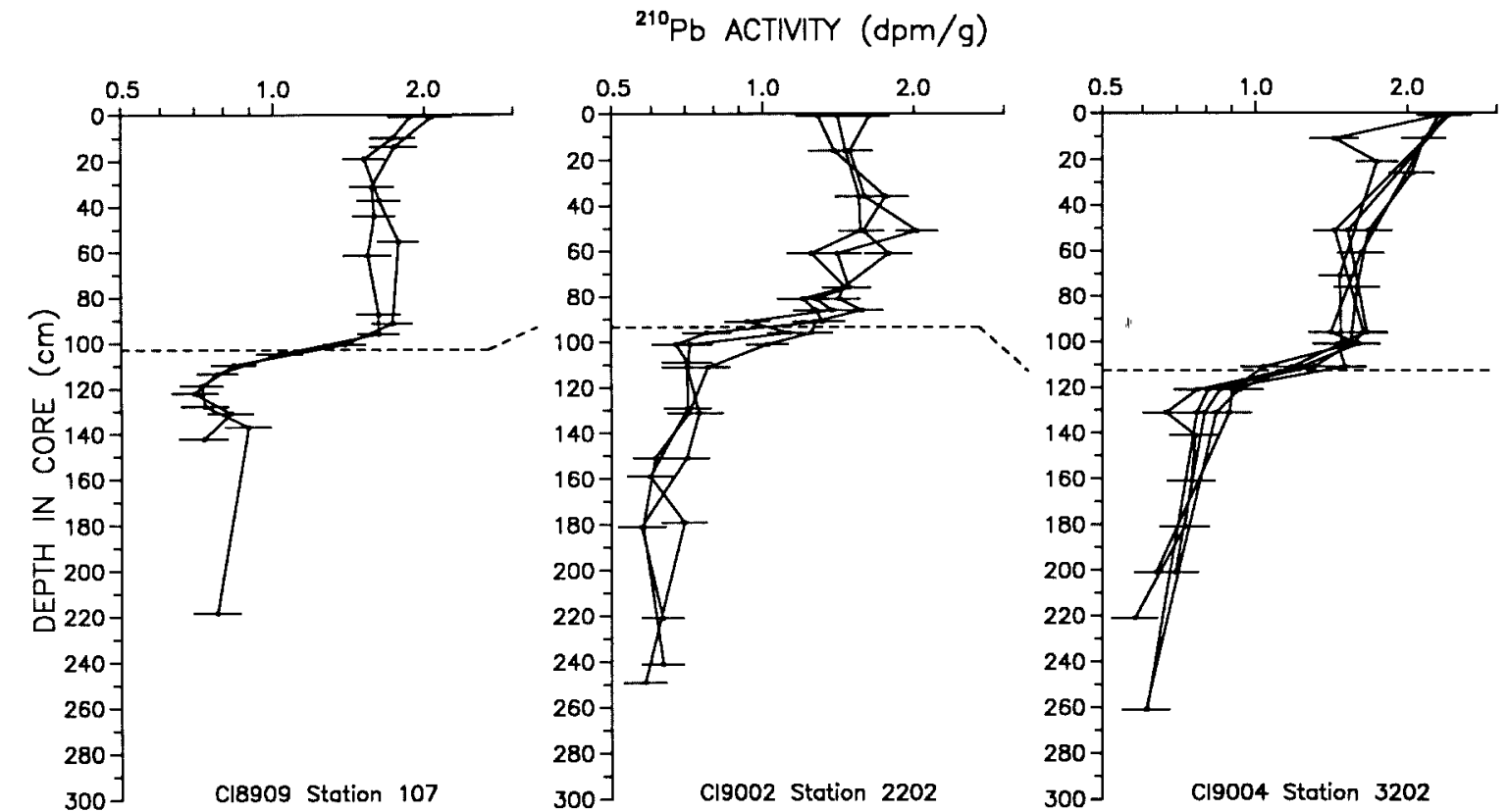

Fig. 2: Profiles of excess ${ }^{210} \mathrm{~Pb}$ activity at a station in the topset region (13 $\mathrm{m}$ water depth) near the Amazon river mouth. Cruises I, II and III were during falling, rising and high stages of the Amazon River discharge, respectively. A surface layer of nearly uniform activity is present throughout the year. Profiles were measured on replicate cores (as shown) during each cruise, and indicate: little small-scale spatial variability in thickness of the surface laver; seasonal variations of about $20 \mathrm{~cm}$. The primary cause of the thick layer is intense physical reworking on time-scales of a few years or less (see text).

layer does result from some sort of physical reworking on time scales of a few years or less (determined from the excess ${ }^{210} \mathrm{~Pb}$ activities).

Punctuation of the stratigraphic record by erosional events is clearly observed in $\mathrm{x}$-radiographs (Fig. 1). Erosional boundaries can be recognized by truncations of strata, and, in some case, of burrows. Corresponding profiles of ${ }^{210} \mathrm{~Pb}$ suggest that significant erosional events have a reoccurrence interval of less than $10 \mathrm{y}$. These events may result from fluctuations in the river discharge or the oceanic processes.

\section{The Subaqueous Foreset Region}

${ }^{210} \mathrm{~Pb}$ accumulation rates reach their highest value (about $10 \mathrm{~cm} \mathrm{y}^{-1}$, averaged over a century) on the foreset region (about 40-60 m water depth) of the Amazon subaqueous delta. In the area of very rapid sedimentation, short-term deposition (not bioturbation) controls profiles of ${ }^{234} \mathrm{Th}$ in the seabed. Deposition rates (averaged over several months) from ${ }^{234} \mathrm{Th}$ measurements are about a centimeter per month (Fig. 3), and are consistent with the longer-term ${ }^{210} \mathrm{~Pb}$ accumulation rates. Particularly intriguing are ${ }^{210} \mathrm{~Pb}$ profiles which reveal quasi-cyclic fluctuations of excess activity with depth in core (Fig. 3). The length scale of these cycles and the ${ }^{234} \mathrm{Th}$ deposition rates suggest that the fluctuations have an annual periodicity. The profiles could reflect fluctuations in scaveng-

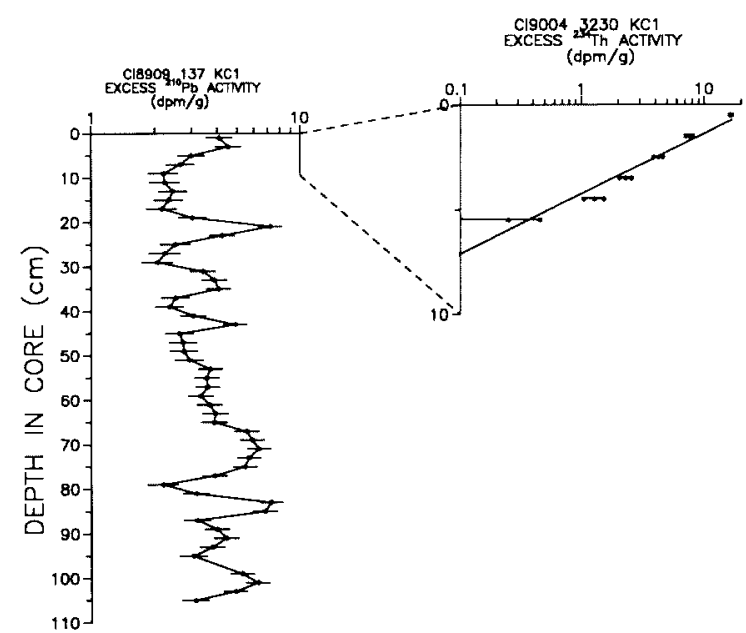

Fig. 3: Profiles of excess ${ }^{210} \mathrm{~Pb}$ and ${ }^{234} \mathrm{Th}$ from a station in the foreset region ( $58 \mathrm{~m}$ water depth). The cyclic fluctuations in the ${ }^{210} \mathrm{~Pb}$ profile may result from variations in ${ }^{210} \mathrm{~Pb}$ scavenging or mudflows (see text). Accumulation rates in this region are about $10 \mathrm{~cm} \mathrm{y}^{-1}$ (averaged over a century). The ${ }^{234}$ Th profile (obtained during peak discharge of the river) indicates a short-term deposition rate of $1.4 \mathrm{~cm} \mathrm{mo}^{-1}$ (averaged over a few months).

ing of dissolved ${ }^{210} \mathrm{~Pb}$ by suspended particles, perhaps controlled by seasonal changes in river discharge or oceanic circulation.

\section{$P_{\text {articularly intriguing }}$} are ${ }^{210} \mathrm{~Pb}$ profiles which reveal quasi-cyclic fluctuations of excess activity with depth in core. 
. . . the decreased

accumulation rates

allow a community of subsurface deposit

feeders to inhabit the deeper portions of the transect.
Detailed coring has been performed along the Open-Shelf Transect from the $40-\mathrm{m}$ to the $70-\mathrm{m}$ isobaths. ${ }^{210} \mathrm{~Pb}$ measurements of surface sediment samples reveal an increase in activity with increasing water depth along the transect, consistent with DeMaster et al. (1986). Examination of $\mathrm{x}$ radiographs has revealed some evidence of mass movement. The existence of mass movement is supported by partial burial of the GEOPROBE tripod at $63 \mathrm{~m}$ along this transect. Therefore, an- other possible explanation for the cyclic ${ }^{210} \mathrm{~Pb}$ profiles is repeated emplacement of lower-activity sediment by down-slope mud flows.

With increased depth along this transect (between $40 \mathrm{~m}$ to $70 \mathrm{~m}$ ), accumulation rates decrease and evidence of bioturbation increases. Cooperative studies with the Seabed Chemistry/Biology group of AmasSeds suggest that the decreased accumulation rates allow a community of subsurface deposit feeders to inhabit the deeper portions of

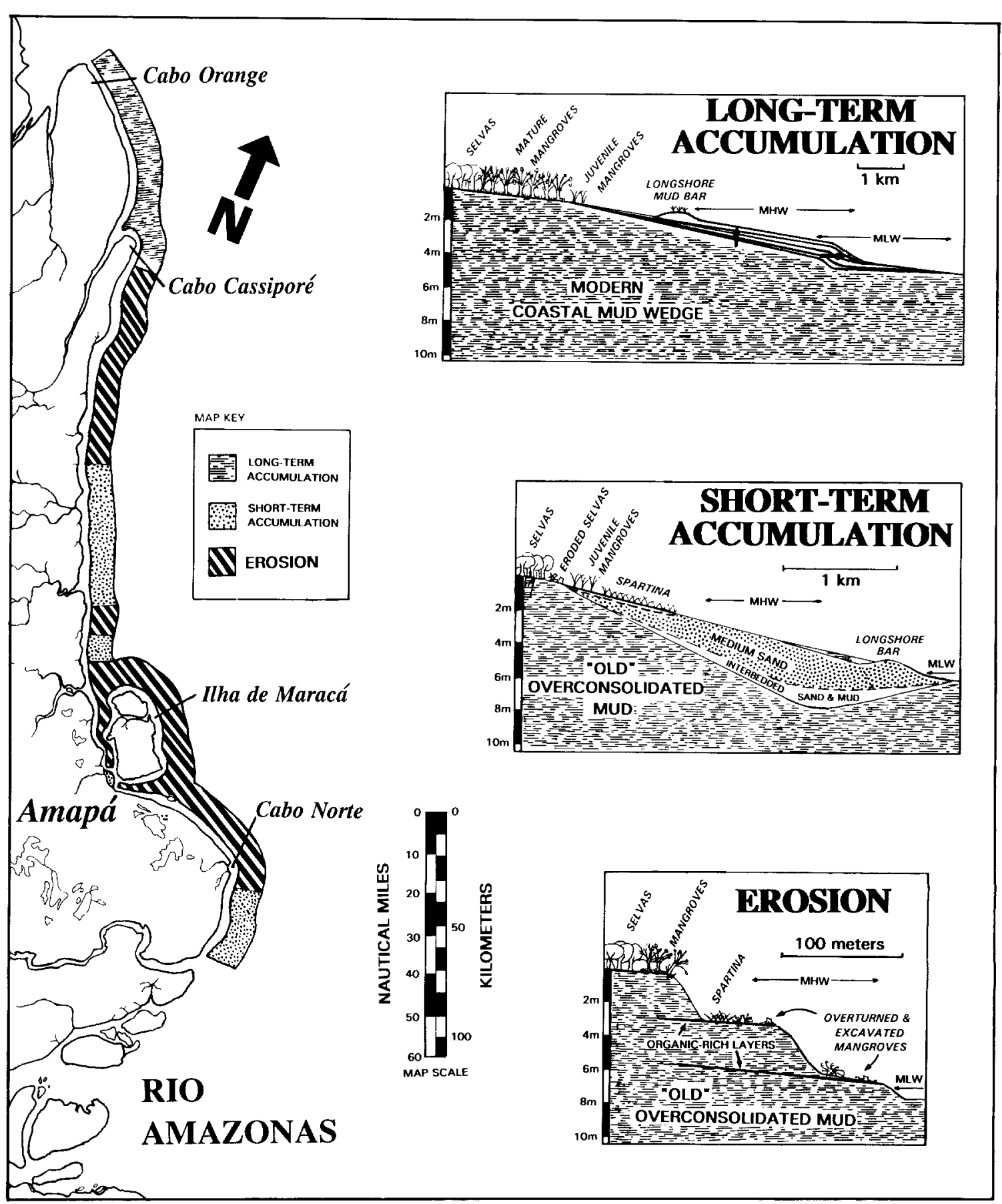

Fig. 4: Descriptions of processes and strata (from vibracores and hand cores) along the coast of Amapá. Erosional shorelines characterize the coast as far north as Cabo Cassiporé, with some localized, shortterm accumulation associated with small rivers. A prograding muddy shoreline is found between Cabo Cassiporé and Cabo Orange. 
... changes in river

discharge, the oceanic

environment, or

perhaps submersion of

the landmass near

Cabo Norte. older deposits were formed about a thousand years ago. The Amazon shelf seaward of Amapá was undergoing erosion of the seabed until about a thousand years ago, when it changed to the present condition of sediment accumulation. The link with the coastal environment is not yet clear, but probably important. The causes could be changes in the river discharge, the oceanic environment, or perhaps submersion of the landmass near Cabo Norte.

In the past, Amazon-shelf research studies using high-resolution seismic equipment were limited to $3.5-\mathrm{kHz}$ profiles, with penetration restricted typically to $20-30 \mathrm{~m}$. The AmasSeds project is using a GEOPULSE system with lower frequency and greater power for penetration to as much as $100 \mathrm{~m}$. One of the discoveries made with this system is the extensive presence of gas deep within the inner-shelf deposits. Farther seaward (Fig. 5), the seismic records indicate multiple stratigraphic units, each about $20 \mathrm{~m}$ thick. The units contain distinct horizons about 5-m thick separating sediment which is acoustically more transparent. Evidence of strata deformation is common. The stratigraphic units may be related to sea-level transgression and regression.

\section{Future Work}

A cruise during the low-discharge period of the Amazon (October-November, 1991) will provide important information for time-series studies examining mechanisms of sediment accumulation. On a separate leg of the cruise, piston coring and seismic profiling will investigate the environmental changes during the past several thousand years and will evaluate the presence of transgressionregression stratigraphic packages on the outer shelf. Coastal studies will focus on the regions near Cabo Orange and Cabo Norte, in order to examine processes of accretion and erosion, respectively. Successes with field work to date suggest that samples and data from all the cruises will require until the end of 1993 for completion of the laboratory phase.

\section{Acknowledgements}

Participation of US scientists was sponsored by the National Science Foundation (OCE8812530), and participation of Brazilian Scientists was sponsored by Conselho Nacional de Desenvolvimento Científico e Tecnológico (CNPq) and Comissão Interministerial para os Recursos do Mar (CIRM). The authors thank the many colleagues who helped with the field and laboratory portions of this research.

\section{References}

DeMaster, D.J., S.A. Kuehl and C.A. Nittrouer, 1986: Effects of suspended sediments on geochemical processes near the mouth of the Amazon River: examination of biological silica uptake and the fate of particle-reactive elements. Cont. Shelf Res., 6, 107-125.

Eisma, D. and H.W. van der Marel, 1971: Marine muds along the Guyana coast and their origin from the Amazon Basin. Contrib. Mineral. Petrol, 31, 321-334.

Faria, L.E.C., A.C. Mendes, H. Vital, M.R. Fereira, O.F.M. Silveira, C.A. Nittrouer, J.M. Rine, M.A. Allison, S.A. Kuehl and M.P. Segall, 1990: Geological evolution of Maracá Island, Amapá coast. and its relation with sea level changes in the north of Brazil, EOS, 71, 1394.

Geyer, W.R., R.C. Beardsley, J. Candela, B. Castro, R.V. Legeckis, S.J. Lentz, R. Limeburner, L. Miranda and J.H. Trowbridge, 1991: The physical oceanography of the Amazon outflow. Oceanography, 4, 8-14.

Kuehl, S.A., D.J. DeMaster and C.A. Nittrouer, 1986: Nature of sediment accumulation on the Amazon continental shelf. Cont. Shelf Res., 6, 209-225.

Nittrouer, C.A., T.B. Curtin and D.J. DeMaster, 1986: Concentration and flux of suspended sediment on the Amazon continental shelf. Cont. Shelf Res., 6, 151174.

and D.J. DeMaster, 1986: Sedimentary processes on the Amazon continental shelf: past, present and future research. Cont. Shelf Res., 6, 5-30.

D.J. DeMaster, A.G. Figueiredo and J.M. Rine, 1991: AmasSeds: An interdisciplinary investigation of a complex coastal environment. Oceanography, 4, 3-7.

Rine, J.M. and R.N. Ginsburg, 1985: Depositional facies of a mud shoreface in Suriname, South America-a mud analogue to sandy shallow-marine deposits. Jour. Sed. Petrol., 55, 633-652. $\square$ 